\title{
Suplementação com vitamina D em lactentes: que evidência?
}

Marisa Carvalho,* Sílvio Barge**

\section{RESUMO}

Objectivo: Determinar se existe evidência de benefícios clínicos na suplementação com vitamina D nos lactentes. Fontes de dados: Base de dados MEDLINE e sítios electrónicos de Medicina Baseada na Evidência.

Métodos de revisão: Pesquisa de normas de orientação clínica, meta-análises, revisões sistemáticas, revisões baseadas na evidência e ensaios clínicos, publicados até Janeiro de 2010, em inglês, francês, espanhol e português, utilizando os termos MeSH: vitamin $D$, dietary supplements. Para avaliar a qualidade dos estudos e a força de recomendação, foi utilizada a escala Strength of Recommendation Taxonomy da American Family Physician.

Resultados: Foram identificados 340 artigos, tendo sido seleccionados nove que cumpriam a totalidade dos critérios de inclusão, dos quais três normas de orientação clínica, duas revisões sistemáticas, uma revisão baseada na evidência, dois consensos de peritos e um estudo de coorte. Não existe consenso acerca da necessidade de suplementação com vitamina D nos lactentes, nem da dose a utilizar. Suplementação com 400UI/L/dia de vitamina D a todos os lactentes em aleitamento materno exclusivo ou que ingiram menos de $1 \mathrm{~L}$ de leite artificial por dia parece ser benéfica e segura.

Conclusão: Neste momento, o mais consensual é a recomendação de suplementação com 400UI/L/dia de vitamina D a todos os lactentes em aleitamento materno exclusivo, ou até que ingiram pelo menos $1 \mathrm{~L}$ de leite artificial por dia, para prevenir o raquitismo. São necessários mais estudos controlados, aleatorizados, de longa duração e boa qualidade que avaliem as necessidades de vitamina $D$ em diferentes populações.

Palavras-chave: Vitamina D; Suplementos Dietéticos; Lactente.

\section{INTRODUÇÃO}



ma nutrição equilibrada é essencial para o crescimento e desenvolvimento harmonioso dos lactentes. Diariamente somos confrontados na consulta com pedidos, por parte dos pais, de prescrição de vitaminas, pois na sua concepção os benefícios das vitaminas reflectem-se num bebé idealizado, bem nutrido, rosado, grande e saudável.

Na comunidade médica, apesar de estar já estabelecido o papel fisiológico das várias vitaminas, existe ainda controvérsia acerca da necessidade da sua suplementação, nomeadamente no que se refere à vitamina $\mathrm{D}$.

\section{Metabolismo da vitamina D}

A vitamina D é uma vitamina lipossolúvel essencial a inúmeros processos fisiológicos. ${ }^{1}$

$\mathrm{O}$ organismo pode obter esta vitamina essencial-

* Interna do internato médico de Medicina Geral e Familiar, USF Mais Saúde. **Interno do internato médico de Medicina Geral e Familiar, USF Lethes. mente a partir de dois mecanismos: ingestão de alimentos ricos em vitamina $\mathrm{D}$ e síntese cutânea. ${ }^{1}$

Através da alimentação podemos obter, a partir de fontes vegetais, ergocalciferol (ou vitamina $\mathrm{D}_{2}$ ) e, a partir de fontes animais, colecalciferol (ou vitamina $\mathrm{D}_{3}$ ). ${ }^{1}$ São especialmente ricos em vitamina $\mathrm{D}$ os peixes gordos, óleo de peixe, gema de ovo. Contudo, o leite humano tem baixa concentração desta vitamina (1-10 $\mathrm{UI} / 250 \mathrm{ml}) .^{2-5}$

A síntese endógena da vitamina $\mathrm{D}$ ocorre na epiderme sob acção da radiação ultra-violeta B (UV-B). ${ }^{3,5}$ Vários factores influenciam este processo, pelo que pessoas que vivem em latitudes mais a norte, em locais de maior poluição, de pele morena, que têm actividades sobretudo em locais fechados, que usam roupas a cobrir quase toda a superfície corporal ou usam protector solar sintetizam menos vitamina $\mathrm{D}$, porque a exposição à radiação solar está limitada. Da mesma forma, a síntese desta vitamina está diminuída no inverno e durante a noite. ${ }^{4}$ 
Tanto a vitamina $\mathrm{D}_{2}$ como a vitamina $\mathrm{D}_{3}$ são hidroxiladas no fígado originando 25-hidroxi-vitamina D (ou calcidiol). Esta pode ser armazenada no tecido adiposo, donde é mobilizada quando as demandas do organismo se sobrepõem à quantidade ingerida. Esta é ainda a principal isoforma em circulação, sendo os seus níveis séricos utilizados como medida das reservas de vitamina D. ${ }^{1}$

O calcidiol é subsequentemente hidroxilado no rim, originando 1,25-dihidroxi-vitamina D (ou calcitriol), a forma biologicamente activa desta vitamina. ${ }^{1,4-8}$

\section{Função da vitamina $D$}

O calcitriol, isoforma biologicamente activa da vitamina $\mathrm{D}$, difunde-se através da membrana celular das células-alvo e liga-se ao seu receptor no citoplasma. O complexo calcitriol-receptor dirige-se para o núcleo onde vai levar à activação ou inibição da transcrição de vários genes. ${ }^{1}$

Ao contrário do que se pensava antigamente, existem receptores para a vitamina $\mathrm{D}$ em muitos tecidos: osso, intestino, sistema nervoso central, sistema imune, pele, próstata, mama e glândulas endócrinas. ${ }^{1,9,10}$

A principal função da vitamina D consiste em manter a homeostasia do cálcio ${ }^{10}$ e consequente promoção da mineralização óssea. ${ }^{6}$

A nível celular, a vitamina $\mathrm{D}$ induz paragem do ciclo celular, diferenciação e apoptose em vários tipos celulares. Recentemente, descobriu-se que vários tecidos para além do rim são capazes de activar a vitamina $\mathrm{D}$, designadamente queratócitos, macrófagos activados, células epiteliais da próstata, mama e cólon. Aparentemente a vitamina $\mathrm{D}$ activada nestes locais extra-renais não é libertada na corrente sanguínea, pelo que se pensa que os seus efeitos extra-esqueléticos se devem sobretudo a acções autócrinas e parácrinas. ${ }^{1}$

\section{Deficiência de vitamina D}

A deficiência de vitamina D é um problema que, embora se estime ser muito prevalente, é pouco reconhecido, porque as suas manifestações clínicas surgem apenas numa fase tardia. Crianças aparentemente saudáveis podem ter deficiência desta vitamina, cujas consequências poderão só ser observadas anos mais tarde. ${ }^{11,12}$

Como seria previsível pela sua importante função no metabolismo ósseo, a consequência mais ampla- mente reconhecida da deficiência de vitamina D consiste no desenvolvimento de raquitismo. ${ }^{8}$ Aumento do risco de osteoporose é também uma consequência importante da deficiência desta vitamina. ${ }^{13}$

Outras doenças mais recentemente associadas a deficiência de vitamina D incluem: hipertensão arterial, ${ }^{14}$ distúrbios musculares, ${ }^{15}$ esclerose múltipla, ${ }^{16}$ diabetes mellitus tipo 1 (DM tipo 1), ${ }^{17}$ infecções micobacterianas, ${ }^{18}$ esquizofrenia ${ }^{19}$ e pré-eclâmpsia. ${ }^{20}$ Doenças alérgicas como asma e rinite também estão relacionadas com deficiência de vitamina D. ${ }^{21}$ Por último, deficiência de vitamina $D$ parece estar também associada ao desenvolvimento de várias neoplasias, ${ }^{22}$ nomeadamente cólon-rectal, ${ }^{23}$ mama $^{1}$ e próstata. ${ }^{7}$

Um aspecto importante a salientar é o facto de, apesar de muitas destas doenças apenas se manifestarem na idade adulta, a disponibilidade de vitamina $\mathrm{D}$ durante os primeiros meses ou anos de vida poder ter impacto significativo no seu desenvolvimento. 13,17,20 $^{2}$

\section{Raquitismo}

Deficiência grave de vitamina D, quando ocorre durante a fase de crescimento, manifesta-se como raquitismo, no qual existe um defeito na mineralização da placa de crescimento. O seu equivalente na idade adulta consiste na osteomalácia. ${ }^{8}$

Não existem dados acerca da prevalência de raquitismo em Portugal. A nível mundial esses dados são de difícil comparação dada a variabilidade de critérios utilizados no seu diagnóstico, a variação temporal da sua frequência e a diversidade populacional. ${ }^{3}$

Manifesta-se por dor óssea, crescimento estatural deficiente, craniotabes (amolecimento dos ossos cranianos), fraqueza muscular (por vezes com atraso do desenvolvimento motor), convulsões (devido a hipocalcemia), fracturas e deformidades esqueléticas típicas, nomeadamente membros inferiores arqueados, edema das ancas, joelhos ou tornozelos, rosário raquítico (devido a edema das articulações costo-condrais) e sulco de Harrison (depressão subcostal). ${ }^{3,8}$

\section{Recomendações da Direcção-Geral da Saúde}

Em Portugal, a Direcção-Geral da Saúde recomenda administração de vitamina $\mathrm{D}$ a todos os lactentes desde a primeira consulta até aos 12 meses. Não há uma dose aconselhada por este mesmo organismo. Esta re- 
comendação não distingue prematuros de recém-nascidos de termo nem lactentes amamentados daqueles alimentados com fórmulas lácteas. ${ }^{24}$

\section{Formulações de vitamina D comercializadas em Portugal}

Actualmente, em Portugal são comercializados três compostos de vitamina D isolada, em formulações adequadas a lactentes, neste caso, em solução oral: alfacalcidiol $(2 \mu \mathrm{g} / \mathrm{ml})$, calcifediol $(0,15 \mathrm{mg} / \mathrm{ml})$ e colecalciferol $(0,5 \mathrm{mg} / \mathrm{ml}){ }^{25}$ Este último é o mais utilizado pelos clínicos para suplementação dos recém-nascidos e uma gota desta preparação equivale a 800 UI de vitamina D.

As alterações nas condições sócio-económicas e nos estilos de vida, acompanhadas de evidência crescente de potenciais impactos da deficiência de vitamina $D$ em diversos órgãos para além do osso, exigem uma actualização acerca da evidência relativa à suplementação em vitamina D nos lactentes.

\section{Objectivo}

Neste contexto, foi elaborada uma revisão sistemática tendo como principal objectivo:

- Determinar se existe evidência de benefícios clínicos na suplementação em vitamina D nos lactentes.

\section{MÉTODOS}

Esta revisão sistemática consistiu numa revisão baseada na evidência, cujos critérios de inclusão e exclusão, fontes de pesquisa e seus resultados são, a seguir, mencionados.

\section{Critérios de inclusão e exclusão}

Foram definidos os seguintes critérios de inclusão:

População: lactentes de termo saudáveis;

Intervenção: administração oral de vitamina $\mathrm{D}$, diariamente;

Comparação: administração de vitamina D versus ausência de intervenção; administração de vitamina D versus placebo;

Resultados: qualquer benefício clínico.

Foram excluídos desta revisão estudos em lactentes com patologia renal, doença hepato-bilio-pancreática ou outros distúrbios da absorção conhecidos, incluindo fibrose cística.

\section{Fontes pesquisadas}

O primeiro passo consistiu na definição, utilizando a base de dados de termos MeSH da PubMed, das palavras-chave para a pesquisa: vitamin $D$ e dietary supplements. Foram ainda pesquisados os descritores para as Ciências da Saúde (DeCS) utilizando a Biblioteca Virtual em Saúde: vitamina D e lactente.

Utilizando estas palavras-chave efectuou-se uma pesquisa de Normas de Orientação Clínica (NOC) e revisões sistemáticas nas seguintes bases de dados: $\mathrm{Na}$ tional Guideline Clearinghouse, Guidelines Finder da National Electronic Library for Health do NHS britânico, Canadian Medical Association Practice Guidelines Infobase, The Cochrane Library, DARE e Bandolier. Foi efectuada ainda uma pesquisa de revisões sistemáticas na PubMed utilizando as mesmas palavras-chave e limitando a busca a artigos em inglês, efectuados em humanos, com idade $<24$ meses. Complementarmente foi efectuada uma pesquisa no Índex de Revistas Médicas Portuguesas, utilizando os termos DeCS (vitamina D e lactente). Finalmente, com o objectivo de procurar estudos mais recentes, ainda não incluídos em revisões, efectuou-se, na PubMed, e utilizando as mesmas palavras-chave, uma pesquisa de estudos clínicos aleatorizados, em inglês, português, espanhol e francês, efectuados em humanos, com idade $<24$ meses, publicados nos últimos 2 anos.

Entre 9 de Fevereiro e 10 de Março de 2010 foi efectuada a pesquisa de artigos publicados de Janeiro de 2000 até Janeiro de 2010.

Para avaliar a qualidade dos estudos e a força de recomendação foi utilizada a escala Strength of Recommendation Taxonomy da American Family Physician.

\section{RESULTADOS}

A pesquisa efectuada resultou na identificação de um total de 340 artigos.

Foram lidos os resumos de todos os artigos e, quando permaneciam dúvidas, o texto integral de alguns deles. Foram assim excluídos os artigos repetidos, aqueles em que se verificava discordância com o objectivo da revisão e, aqueles que não cumpriam a totalidade dos critérios de inclusão. Deste modo obtiveram-se oito artigos (três NOC, , ,4,11 duas revisões sistemáticas, ${ }^{3,10}$ uma revisão baseada na evidência ${ }^{8}$ e dois consensos de peritos $^{5,7}$ ) para incluir na revisão. 
Posteriormente foram ainda consultadas as referências bibliográficas desses oito artigos à procura de outros estudos que avaliassem o papel da suplementação em vitamina D em lactentes, no que se refere aos efeitos mais recentemente reconhecidos da vitamina D. Foi desta forma identificado mais um estudo que cumpria os critérios de inclusão, um estudo de coorte, ${ }^{17}$ o qual foi também incluído na revisão.

Assim, a pesquisa efectuada resultou na inclusão de um total de nove artigos nesta revisão: três NOC, ${ }^{2,4,11}$ duas revisões sistemáticas, ${ }^{3,10}$ uma revisão baseada na evidência, ${ }^{8}$ dois consensos de peritos ${ }^{5,7}$ e um estudo de coorte. ${ }^{17}$

Os benefícios da suplementação em vitamina $D$ podem dividir-se em dois grandes grupos: prevenção do raquitismo e, prevenção de outras doenças mais recentemente associadas a deficiência de vitamina D.

O Quadro I resume os principais resultados dos artigos seleccionados.

\section{DISCUSSÃO}

\section{Suplementação com vitamina D na prevenção do raquitismo}

Uma revisão sistemática, efectuada por Cranney Aet al em 2007 recomenda suplementação com 400 $\mathrm{UI} / \mathrm{L} /$ dia de vitamina $\mathrm{D}$ de todos os lactentes amamentados e, sugere que doses mais elevadas são necessárias para lactentes com factores de risco para deficiência de vitamina $\mathrm{D}$ (ex. lactentes que vivem em latitudes elevadas, que nascem no fim do Inverno). Esta recomendação teve como base dois factos importantes demonstrados pelos estudos incluídos nessa mesma revisão: existe uma dose-resposta entre a suplementação de vitamina D e a concentração de 25(HO)D e, existe evidência clara de uma associação entre níveis baixos de 25(HO)D e raquitismo. Contudo, existe evidência inconsistente de um nível, a partir do qual deixa de ocorrer raquitismo e, consequentemente de um nível de ingestão ideal de vitamina D. Esta inconsistência deve-se à imprecisão dos métodos utilizados na determinação da concentração sérica de $25(\mathrm{HO}) \mathrm{D}$, à variabilidade dos outcomes utilizados para determinar esse nível desejado e, a factores de confundimento (ex. dieta com baixo teor de cálcio produz um nível falsamente elevado de vitamina D necessária a determinado outcome) ${ }^{10}$ Esta revisão teve um outcome orientado para a doença (DOE), que foi a concentração sérica de 25(HO)D, pelo que lhe atribuímos um Nível de evidência (NE) 3.

Outra revisão sistemática, efectuada em 2007 por Lerch e Meissner considera existirem poucos estudos efectuados em lactentes acerca da prevenção do raquitismo. No entanto, aconselha a disponibilização de medidas para prevenir o raquitismo (vitamina D ou cálcio) a todas as crianças com menos de 2 anos, mas não refere doses. ${ }^{3}$ Apesar de os estudos clínicos incluídos nesta revisão serem aleatorizados controlados, devido ao facto de serem de pequena dimensão e os resultados apresentados serem apenas moderadamente consistentes, atribuímos a esta um NE 2.

Uma NOC da American Academy of Pediatrics (AAP) publicada em 2008 recomenda suplementação com 400 UI/L/dia de vitamina D de todos os lactentes exclusivamente amamentados e daqueles que ingerem menos de $1 \mathrm{~L}$ diário de fórmulas lácteas enriquecidas em vitamina D. A suplementação deve ser iniciada nos primeiros dias de vida. Esta recomendação baseia-se em vários factos: estudos recentes sugerem que 200 $\mathrm{UI} / \mathrm{L} /$ dia de vitamina D (dose recomendada pela AAP até 2008) são provavelmente insuficientes para prevenir a deficiência desta vitamina; a principal fonte de vitamina D é a exposição aos raios UV-B, como evidências epidemiológicas sugerem que a idade em que a exposição directa à luz solar é iniciada é mais importante que a exposição solar total para o desenvolvimento de cancro da pele, as novas normas de orientação clínica recomendam que lactentes menores de 6 meses não devem ser expostos à luz solar; o leite materno tem menos de $25 \mathrm{UI} / \mathrm{L}$ de vitamina D; as fórmulas para lactentes vendidas nos EUA têm pelo menos 400 UI/L desta vitamina. ${ }^{4}$ A necessidade de uma dose superior à recomendada previamente deve-se provavelmente ao estilo de vida moderno em que as pessoas passam muito tempo dentro de edifícios e há uma maior consciencialização acerca dos riscos da exposição solar excessiva. ${ }^{4}$

Os autores de uma NOC da Health Canada publicada em 2004, após avaliação da publicação 1997 Dietary Reference Intakes, que considera adequada, para os lactentes, uma ingestão de $200 \mathrm{UI} / \mathrm{L} /$ dia de vitamina D, decidiram manter a recomendação de suplementação com $400 \mathrm{UI} / \mathrm{L} /$ dia de vitamina $\mathrm{D}$ a todos os recém-nas- 
QUADRO I. Tabela resumo dos artigos incluídos na revisão

Revisões Sistemáticas

\begin{tabular}{l|l|l}
\hline Citação & Resultados & NE \\
\hline $\begin{array}{l}\text { Cranney A et al, } \\
2007\end{array}$ & $\begin{array}{l}\text { - suplementação com } 400 \text { UI/L/dia de vitamina D de todos os lactentes amamentados } \\
\text { - doses mais elevadas para lactentes com factores de risco para deficiência de vitamina D }\end{array}$ & 3 \\
\hline $\begin{array}{l}\text { Lerch e Meissner, } \\
2007\end{array}$ & $\begin{array}{l}\text { - devem ser disponibilizadas medidas para prevenir o raquitismo (vitamina D ou cálcio) a todas as } \\
\text { crianças com menos de } 2 \text { anos } \\
\text { - devem ser efectuados estudos prospectivos para investigar o papel, a longo-prazo, da suplementação } \\
\text { em vitamina D durante a infância, na ocorrência de doenças auto-imunes e cancro }\end{array}$ & 2 \\
\hline
\end{tabular}

Estudos de coorte

\begin{tabular}{l|l|l|l|l}
\hline Citação & População & Intervenção & Resultados & NE \\
\hline $\begin{array}{l}\text { Hyppönen E et al } \\
\text { em } 2001\end{array}$ & $\begin{array}{l}\text { recém-nascidos durante 1966 } \\
\text { em Oulu e Lapland (10.360) }\end{array}$ & $\begin{array}{l}\text { suplementação com 2000 UI/L/ } \\
\text { /dia vit D vs não suplementação } \\
\text { ou suplementação com dose } \\
\text { inferior }\end{array}$ & $\begin{array}{l}\text { Diabetes mellitus tipo } 1 \text { está } \\
\text { associada a baixa ingestão de } \\
\text { vitamina D nos lactentes }\end{array}$ & 2 \\
\hline
\end{tabular}

\section{Normas de Orientação clínica}

\begin{tabular}{|c|c|c|c|}
\hline Citação & \multicolumn{3}{|c|}{ Recomendações } \\
\hline $\begin{array}{l}\text { American } \\
\text { Academy of } \\
\text { Pediatrics, } 2008\end{array}$ & \multicolumn{3}{|c|}{$\begin{array}{l}\text { - todos os lactentes em aleitamento materno exclusivo e aqueles que ingerem menos de } 1 \mathrm{~L} \text { diário de } \\
\text { fórmulas lácteas enriquecidas em vitamina } D \text { devem ser suplementados com } 400 \text { UI/L/dia de vitamina } D \text {, } \\
\text { desde os primeiros dias de vida }\end{array}$} \\
\hline $\begin{array}{l}\text { Health Canada, } \\
2004\end{array}$ & \multicolumn{3}{|c|}{$\begin{array}{l}\text { - todos os recém-nascidos no Canadá devem ser suplementados com } 400 \mathrm{UI} / \mathrm{L} / \text { dia de vitamina } \mathrm{D} \text {, desde a } \\
\text { nascença até aos } 12 \text { meses de idade ou até a dieta fornecer } 400 \mathrm{UI} / \mathrm{L} / \text { dia de vitamina } D\end{array}$} \\
\hline $\begin{array}{l}\text { First Nations, } \\
\text { Inuit and Métis } \\
\text { Health } \\
\text { Committee } \\
2007-01,2007\end{array}$ & \multicolumn{3}{|c|}{$\begin{array}{l}\text { - todos os lactentes no primeiro ano de vida devem ser suplementados com } 400 \text { UI/L/dia de vitamina D } \\
\text { (força de recomendação A) } \\
\text { - a dose deve ser aumentada para } 800 \mathrm{UI} / \mathrm{L} / \text { dia entre Outubro e Abril nos lactentes que vivem a norte do } \\
\text { paralelo } 55^{\circ} \text { e, entre os paralelos } 40^{\circ} \text { e } 55^{\circ} \text { nos lactentes com outros factores de risco para deficiência de } \\
\text { vitamina D para além da latitude (força de recomendação B) } \\
\text { - as necessidades de vitamina D estão relacionadas com o peso, logo, são necessários estudos para } \\
\text { determinar as doses desejáveis de vitamina D de acordo com este parâmetro (força de recomendação A) } \\
\text { - vitamina D pode estar envolvida no desenvolvimento de diversas doenças sistémicas, muitas das quais se } \\
\text { manifestam tardiamente na idade adulta (baseado em artigos com nível de evidência II-III) }\end{array}$} \\
\hline \multicolumn{4}{|c|}{ Revisões baseadas na evidência } \\
\hline Citação & \multicolumn{3}{|c|}{ Resultados } \\
\hline $\begin{array}{l}\text { Kulie Tet al, } \\
2009\end{array}$ & \multicolumn{3}{|c|}{$\begin{array}{l}\text { - todos os lactentes em aleitamento materno exclusivo devem ser suplementados com } 400 \mathrm{UI} / \mathrm{L} / \mathrm{dia} \text { de } \\
\text { vit. } \mathrm{D} \text { com início nos primeiros dias de vida até que a ingestão de leite artificial seja superior a } 1 \mathrm{~L} \text { por dia. }\end{array}$} \\
\hline \multicolumn{4}{|c|}{ Consensos de Perito } \\
\hline \multicolumn{2}{|l|}{ Citação } & Resultados & NE \\
\hline \multicolumn{2}{|c|}{$\begin{array}{l}\text { Current Opinion in } \\
\text { Clinical Nutrition and } \\
\text { Metabolic Care, } 2009\end{array}$} & $\begin{array}{l}\text { - todos os lactentes amamentados devem ser suplementados com } 400 \mathrm{UI} / \mathrm{L} / \text { dia de vitamina } \mathrm{D} \\
\text { desde os primeiros dias de vida até que ingiram mais de } 1 \mathrm{~L} \text { de leite de fórmula por dia }\end{array}$ & 3 \\
\hline \multicolumn{2}{|c|}{$\begin{array}{l}\text { Prevention and } \\
\text { treatment of infant and } \\
\text { childhood vitamin D } \\
\text { deficiency in Australia } \\
\text { and New Zealand: a } \\
\text { consensus statement, } \\
2006\end{array}$} & $\begin{array}{l}\text { - não deve ser efectuada suplementação de rotina a todos lactentes, visto serem uma } \\
\text { população de baixo risco } \\
\text { - lactentes de pele escura ou filhos de mães que usam burca devem ser suplementados com } \\
400 \text { UI/L/dia de vitamina D }\end{array}$ & 3 \\
\hline
\end{tabular}

NE: Nível de Evidência 
cidos no Canadá, desde a nascença até aos 12 meses de idade ou até a dieta fornecer $400 \mathrm{UI} / \mathrm{L} /$ dia de vitamina D. Esta decisão teve como base as seguintes razões: a maior latitude do Canadá e as práticas actuais relacionadas com a protecção solar que diminuem a síntese de vitamina $D$, uma vez que a luz solar é a principal fonte de vitamina $\mathrm{D}$; a elevada prevalência de raquitismo e deficiência de vitamina $D$; a segurança da suplementação com vitamina $\mathrm{D}_{2}$ até $1000 \mathrm{UI} / \mathrm{L} /$ dia. $^{2}$

Outra NOC do First Nations, Inuit and Métis Health Committee 2007-01 publicada em 2007 recomenda suplementação com $400 \mathrm{UI} / \mathrm{L} /$ dia de vitamina $\mathrm{D}$ a todos os lactentes no primeiro ano de vida (força de recomendação A). A dose deve ser aumentada para 800 $\mathrm{UI} / \mathrm{L} /$ dia entre Outubro e Abril, nos lactentes que vivem a norte do paralelo $55^{\circ} \mathrm{e}$, entre os paralelos $40^{\circ}$ e $55^{\circ}$ nos lactentes com outros factores de risco para deficiência de vitamina D para além da latitude (ex. lactentes de pele escura, com excesso de peso, em aleitamento materno exclusivo) (força de recomendação B). Há ainda evidência que as necessidades de vitamina D estão relacionadas com o peso, tendo em conta que os lactentes triplicam o peso no primeiro ano de vida, são necessários estudos para determinar as doses desejáveis de vitamina $\mathrm{D}$ de acordo com este parâmetro no primeiro ano de vida (força de recomendação A). ${ }^{11}$

Uma revisão baseada na evidência efectuada por Kulie T et al em 2009 recomenda suplementação dos lactentes em aleitamento materno exclusivo com 400 $\mathrm{UI} / \mathrm{L} /$ dia de vitamina $\mathrm{D}$, com início nos primeiros dias de vida até que a ingestão de leite artificial seja superior a 11/dia. Esta recomendação é baseada nas NOC da AAP. $^{8}$

Um consenso de peritos publicado em 2009 recomenda, apesar de provavelmente doses menores serem suficientes para prevenir o raquitismo, suplementação com $400 \mathrm{UI} / \mathrm{L} /$ dia de vitamina $\mathrm{D}$ a todos os lactentes amamentados, visto que esta dose é segura. A suplementação deve ser iniciada nos primeiros dias de vida e não é necessária nos lactentes que ingerem mais de $1 \mathrm{~L}$ de fórmula láctea. A este artigo atribuímos um NE 3 . $^{7}$

Um consenso de peritos que estabelece as recomendações para a prevenção da deficiência de vitamina D na Austrália e Nova Zelândia publicado em 2006 não recomenda suplementação de rotina a todos lactentes, visto serem uma população de baixo risco (ex- posição solar abundante durante todo o ano e pele clara), excepto lactentes de pele escura ou filhos de mães que usam burca que devem ser suplementados com 400 UI/L/dia de vitamina D. A esta publicação atribuímos um NE $3 .^{5}$

\section{Suplementação com vitamina D na prevenção de outras doenças}

A NOC do First Nations, Inuit and Métis Health Committee 2007-01 refere, embora com base em artigos com nível de evidência II-III, que deficiência de vitamina D pode estar envolvida no desenvolvimento de diversas doenças sistémicas, muitas das quais se manifestam tardiamente na idade adulta. ${ }^{11}$

A revisão efectuada por Lerch e Meissner sugere que devem ser efectuados estudos prospectivos para investigar o papel a longo-prazo da suplementação em vitamina D durante a infância, na ocorrência de doenças auto-imunes e cancro. ${ }^{3}$

Um estudo de coorte, publicado por Hyppönen E et al em 2001, estudou cerca de 10.000 crianças que nasceram em 1966 em Oulu e Lapland (norte da Finlândia). As mães dessas crianças foram inquiridas acerca da suplementação em vitamina $\mathrm{D}$ desses lactentes no primeiro ano de vida e, posteriormente, quando esses indivíduos atingiram 30 anos estudou-se a prevalência de DM tipo 1 nesse grupo, de acordo com a suplementação em vitamina D que tinham efectuado. Assim, conclui-se que DM tipo 1 está associada a baixa ingestão de vitamina $\mathrm{D}$ nos lactentes. $\mathrm{O}$ artigo refere ainda que estes resultados podem ser extrapolados para outras populações apesar de a suplementação em vitamina $\mathrm{D}$ ser mais benéfica em populações com concentrações sub-óptimas de vitamina $\mathrm{D}$, como a população do norte finlandês. A dose necessária para prevenir a DM tipo 1 parece ser mais elevada do que aquela para prevenir o raquitismo. ${ }^{17} \mathrm{~A}$ este estudo atribuímos um NE 2.

\section{CONCLUSÃO}

Perante os resultados obtidos:

- Parece razoável recomendar na população portuguesa suplementação com 400 UI/L/dia de vitamina $\mathrm{D}$ a todos os lactentes em aleitamento materno exclusivo ou até que estes ingiram pelo menos $1 \mathrm{~L}$ de leite artificial diariamente. Esta conclusão é apoiada por duas revisões sistemáticas (com NE 2 e 3), três 
NOC, uma revisão baseada na evidência e um consenso de peritos (com NE 3), e contrariada por um consenso de peritos (com NE 3), pelo que lhe atribuímos uma força de recomendação $\mathrm{B}$.

- Pelos estudos disponíveis até ao momento não existem riscos para a saúde com suplementação até 1000 UI/L/dia de vitamina D.

- O desenvolvimento de diversas doenças crónicas, nomeadamente doenças auto-imunes, neoplasias e DM tipo 1 parece estar relacionado com a suplementação de vitamina D na infância. Esta conclusão tem como base apenas um estudo de coorte (com NE 2) com opinião favorável e uma revisão sistemática (com NE 2) que aconselha a realização de estudos para averiguar esta possível relação, pelo que lhe atribuímos uma força de recomendação C. Um consenso de peritos sugere, no caso de esta associação existir, que doses superiores a $400 \mathrm{UI} / \mathrm{L} /$ dia parecem ser necessárias para prevenir essas doenças.

Dado que a formulação de colecalciferol disponível em Portugal tem 800UI por gota, sugere-se a suplementação com uma gota de colecalciferol a $0,5 \mathrm{mg} / \mathrm{ml}$ em dias alternados. No futuro, se mais estudos confirmarem que 400UI de vitamina D por dia são suficientes, poderá ter interesse sugerir ao Infarmed a comercialização de uma formulação mais diluída, que permita administrar 400UI de colecalciferol por gota.

Apesar de, aparentemente, pelos dados apresentados, a suplementação com vitamina $\mathrm{D}$ a todos os lactentes ser consensual, é de salientar que as revisões, bem como as NOC existentes baseiam-se num número escasso de estudos originais.

Como não há dados acerca da prevalência de raquitismo em Portugal, não é possível saber se as doses actualmente utilizadas estão a ser eficazes para prevenir essa doença. No entanto, é de salientar que não há uma uniformização das doses prescritas entre a comunidade médica portuguesa, pelo que essa análise também seria difícil.

Para que a conduta médica seja mais uniformizada e adequada, ou seja, mais baseada na evidência, no que respeita à prescrição de vitamina $\mathrm{D}$, são necessários mais estudos acerca das necessidades desta vitamina em diferentes populações, nomeadamente em Portugal, uma vez que múltiplos factores influenciam a síntese cutânea de vitamina $\mathrm{D}$ (a latitude, a cor da pele, a poluição ambiental...) e, além disso, a ingestão de alimentos ricos em vitamina D está muito dependente de factores sócio-culturais.

São ainda necessários estudos controlados, aleatorizados, de longa duração e boa qualidade que avaliem a utilidade da suplementação em vitamina D e a dosagem necessária para a prevenção das doenças mais recentemente associadas a deficiência de vitamina $\mathrm{D}$ (hipertensão arterial, distúrbios musculares, esclerose múltipla, DM tipo 1, infecções micobacterianas, esquizofrenia, pré-eclâmpsia, doenças alérgicas e várias neoplasias).

\section{REFERÊNCIAS BIBLIOGRÁFICAS}

1. Welsh J, Wietzke JA, Zinser Gm, Byrne B, Smith K, Narvaez C. Vitamin D-3 receptor as a target for breast cancer prevention. J Nutr 2003 Jul; 133 (7 Suppl): 2425S-2433S.

2. Health Canada. Vitamin D supplementation for breastfed infants: 2004 Health Canada Recommendation. Disponível em: http://www.hcsc.gc.ca/fn-an/alt_formats/hpfb-dgpsa/pdf/nutrition/vita_d_supp-eng.pdf [acedido em 9/02/2010].

3. Lerch C, Meissner T. Interventions for the prevention of nutritional rickets in term born children. Cochrane Database of Syst Rev 2007 Oct 17; (4): CD006164.

4. Wagner $\mathrm{CL}$, Greer FR, and the Section on Breastfeeding and Committee on Nutrition. Prevention of rickets and vitamin D deficiency in infants, children and adolescents. Pediatrics 2008 Nov; 122 (5): 1142-52.

5. Munns C, Zacharin MR, Rodda CP, Batch JA, Morley R, Cranswick NE, et al. Prevention and treatment of infant and childhood vitamin $D$ deficiency in Australia and New Zealand: a consensus statement. Med J Aust 2006 Sep 4; 185 (5): 268-72.

6. Barrett EJ, Barrett P.The parathyroid glands and vitamin D. In: Boron F, Boulpaep E, editors. Medical Physiology. Philadelphia, PA: Saunders, Elsevier Science; 2003. p. 1086-101.

7. Mimouni FB, Shamir R. Vitamin D requirements in the first year of life. Curr Opin Clin Nutr Metab Care 2009 May; 12 (3): 287-92.

8. Kulie T, Groff A, Redmer J, Hounshell J, Schrager S. Vitamin D: an evidencebased review. J Am Board Fam Med 2009 Nov-Dec; 22 (6): 698-706.

9. Peehl DM, Krishnan AV, Feldman D. Pathways mediating the growth-inhibitory actions of vitamin D in prostate cancer. J Nutr 2003 Jul; 133 (7 Suppl): 2461S-2469S.

10. Cranney A, Horsley T, O'Donnell S, Weiler HA, Puil L, Ooi DS, et al. Effectiveness and safety of vitamin $D$ in relation to bone health. Evidence Report/Technology Assessment No. 158 (Prepared by the University of Ottawa Evidence-based Practice Center (UO-EPC) under Contract No. 29002-0021.AHRQ Publication No.07-E013. Rockville, MD:Agency for Healthcare Research and Quality; 2007. Disponível em: http://www.ahrq.gov/ downloads/pub/evidence/pdf/vitamind/vitad.pdf [acedido em 11/02/2010].

11. First Nations, Inuit and Métis Health Committee 2007-01.Vitamin D supplementation: recommendations for Canadian mothers and infants. Paediatr Child Health 2007 Sep; 12 (7): 583-98. 
12. Gordon CM, Feldman HA, Sinclair L, Williams AL, Kleinman PK, Perez-Rossello J, et al. Prevalence of vitamin $D$ deficiency among healthy infants and toddlers. Arch Pediatr Adolesc Med 2008 Jun; 162 (6): 505-12.

13. Holick MF.Vitamin D: a millenium perspective. J Cell Biochem 2003 Feb 1; 88 (2): 296-307.

14. Fuller KE, Casparian JM.Vitamin D: balancing cutaneous and systemic considerations. South Med J 2001 Jan; 94 (1): 58-64.

15. Bischoff HA, Stähelin HB, Dick W, Akos R, Knecht M, Salis C, et al. Effects of vitamin $D$ and calcium supplementation on falls: a randomized controlled trial. J Bone Miner Res 2003 Feb; 18 (2): 343-51.

16. Munger KL, Zhang SM, O'Reilly E, Hernán MA, Olek MJ, Willett WC, et al. Vitamin $D$ intake and incidence of multiple sclerosis. Neurology 2004 Jan $13 ; 62$ (1): 60-5.

17. Hyppönen $E$, Läärä $E$, Reunanen A, Järvelin MR, Virtanen SM. Intake of vitamin D and risk of type 1 diabetes: a birth-cohort study. Lancet $2001 \mathrm{Nov}$ 3; 358 (9292): 1500-3.

18. Martineau AR, Wilkinson RJ, Wilkinson KA, Newton SM, Kampmann B, Hall $B$, et al. A single dose of vitamin $D$ enhances immunity to mycobacteria. Am J Respir Crit Care Med 2007 Jul 15; 176 (2): 208-13.

19. McGrath J, Saari K, Hakko H, Jokelainen J, Jones $P$, Järvelin MR, et al. Vitamin $D$ supplementation during the first year of life and risk of schizophrenia: a Finnish birth cohort study. Schizophr Res 2004 Apr 1; 67 (2-3): 23745.

20. Hyppönen E, Hartikainen AL, Sovio U, Järvelin MR, Pouta A. Does vitamin $\mathrm{D}$ supplementation in infancy reduce the risk of pre-eclampsia? Eur J Clin Nutr 2007 Sep; 61 (9): 1136-9.

21. Hyppönen E, Sovio U,Wjst M, Patel S, Pekkanen J, H $\Omega$ artikainen AL, et al. Infant vitamin D supplementation and allergic conditions in adulthood: north- ern Finland birth cohort 1966. Ann NY Acad Sci 2004 Dec; 1037: 84-95.

22. Holick MF.Vitamin D: its role in cancer prevention and treatment. Prog Biophys Mol Biol 2006 Sep; 92 (1): 49-59.

23. Grant WB, Garland CF. A critical review of studies on vitamin $D$ in relation to colorectal cancer. Nutr Cancer 2004; 48 (2): 115-23.

24. Direcção-Geral da Saúde - Divisão de Saúde Materna, Infantil e dos Adolescentes. Saúde Infantil e Juvenil: Programa-tipo de actuação. $2^{\mathrm{a}}$ ed. Lisboa: Direcção-Geral da Saúde; 2005. Disponível em: http://www.dgs.pt/upload/membro.id/ficheiros/i008188.pdf [acedido em 9/03/2010].

25. Prontuário terapêutico. Disponível em: http://www.infarmed.pt/prontuario/index.php [acedido em 10/03/2010].

26. Ebell MH, Siwek J,Weiss BD, Woolf SH, Susman J, Ewigman B, et al. Strength of recommendation taxonomy (SORT): a patient-centered approach to grading evidence in the medical literature. Am Fam Physician 2004 Feb 1; 69 (3): 548-56.

\section{CONFLITOS DE INTERESSE}

As autoras declaram não possuir qualquer tipo de conflito de interesses.

\author{
ENDEREÇO PARA CORRESPONDÊNCIA \\ Marisa Rocha Carvalho \\ Loteamento do Campo de Golfe, n. ${ }^{\circ} 56$ B \\ Santo Amaro - Fornelos \\ 4990-620 Ponte de Lima \\ E-mail: marisacarvalho6@gmail.com
}

Recebido em 05/11/2010

Aceite para publicação em 01/05/2011

\section{ABSTRACT}

\section{VITAMIN D SUPPLEMENTATION IN INFANTS: WHAT IS THE EVIDENCE?}

Objective: To determine if there is evidence of clinical benefit for vitamin $D$ supplementation in infants. Sources: MEDLINE data base and Evidence Based Medicine electronic sites.

Review methods: A search for clinical practice guidelines, meta-analyses, systematic reviews, evidence-based reviews and clinical trials published before January 2010, in English, French, Spanish and Portuguese was performed using the MeSH terms: "vitamin D" and "dietary supplements". The Strength of Recommendation Taxonomy scale of the American Family Physician was used to assess the quality of the studies and the strength of the recommendation.

Results: We identified 340 articles, but only nine met all of our inclusion criteria. These consisted of three clinical practice guidelines, two systematic reviews, an evidence-based review, a consensus statement of two experts and one cohort study. No agreement was found regarding the need for vitamin $D$ supplements or the recommended dose. Vitamin D supplementation with 400 IU per day for all infants who are exclusively breastfed or who ingest less than one liter of formula milk per day seems beneficial and safe.

Conclusion: Currently, the most common recommendation for preventing rickets is the provision of $400 \mathrm{IU}$ of vitamin D per day to infants who are exclusively breastfed, or who are fed with at least one liter of milk a day. Additional controlled, randomized, long-term high quality studies are necessary to assess the need for vitamin D supplementation in different populations.

Keywords: Vitamin D; Dietary Supplements, Infant. 